Revista de Economia Política, vol. 30, $n^{\circ} 3$ (119), pp. 511-531, julho-setembro/2010

\title{
Situando o desenvolvimento rural no Brasil: o contexto e as questões em debate
}

SERGIO SCHNEIDER*

Addressing rural development discussions in Brazil: context and issues of debate. The work analyzes the main theoretical trends and subjects that integrate the recent Brazilian debate about rural development. We agued that the agenda of the rural development in Brazil, on which actively participate scholars, organizations and institutions, have been formulated by the State and the public politics implemented since the beginning of the 1990. Among the factors that had influenced the emergency of the debate about rural development is distinguished the increasing social and political legitimating of family farming and the agrarian reform, the reorientation of the state policies, the increasing sharply political and ideological quarrels with the agribusiness wing and the matters about sustainability. It is also argued that the analytical and interpretative references that have being used by the scholars are still diffuse and varied, but has been capable to influence the policy makers.

Keywords: rural development; State; policies; family farming; social theory.

JEL: Q18; Z1; Q38; B25.

\section{INTRODUÇÃO}

Neste trabalho pretende-se fazer uma reflexão sobre as principais tendências e temas que estão animando o debate brasileiro recente sobre o tema desenvolvimento rural. A ideia, fundamentalmente, consiste em descrever e caracterizar o contexto histórico em que o debate corrente sobre o desenvolvimento rural emergiu no Brasil, indicando-se alguns elementos das mudanças políticas, sociais e econômicas que estão na sua raiz. Além disso, buscar-se-á situar as principais perspecti-

\footnotetext{
* Professor da UFRGS, Departamento de Sociologia e membro permanente dos Programas de Pós-Graduação em Sociologia e Desenvolvimento Rural. Bolsista PQ-CNPq. E-mail: schneide@ufrgs.br. Submetido: Agosto 2007; Aprovado: Março 2009.
} 
vas analíticas que vêm orientando os estudiosos e pesquisadores na interpretação dos processos de mudança social que estão ocorrendo no espaço rural.

Durante muito tempo, o desenvolvimento rural foi associado ao conjunto de ações do Estado e dos organismos internacionais destinadas à intervenções nas regiões rurais pobres que não conseguiam se integrar ao processo de modernização agrícola via substituição de fatores de produção considerados atrasados (Navarro, 2001). Esta foi a tônica da intervenção no meio rural do Brasil e de outros países na América Latina no período conhecido pela vigência da ideologia da "revolução verde", que preconizava ações de intervenção dirigidas e orientadas, geralmente de caráter compensatório, que eram vistas como a solução para os agricultores que não conseguiam se modernizar tecnologicamente nem integrar-se ao conjunto da economia através da indústria, comércio e serviços. No Brasil, as políticas de "desenvolvimento rural integrado" (PDRI) eram apontadas como a solução viável para as regiões atrasadas, sendo exemplos eloquentes as ações de colonização e assentamento humano na Amazônia e as frentes de trabalho de combate a seca no Nordeste.

Esta forte identificação do desenvolvimento rural com a agenda das ações de intervenção do Estado ou das agências de desenvolvimento, acabou afastando muitos pesquisadores e estudiosos deste tema, por considerá-lo excessivamente político e normativo. Isto fez com que os estudos rurais brasileiros, especialmente os acadêmicos, deixassem de lado o tema do desenvolvimento rural tout court que passou a ser identificado com políticas de intervenção no meio rural, especialmente em regiões pobres. Somente a partir da década de 1990, uma mudança de enfoque e de entendimento sobre o desenvolvimento rural passou a ganhar espaço no Brasil, revitalizando o tema e gerando novas abordagens.

A partir deste período, as políticas públicas e discussões teóricas sobre desenvolvimento rural reemergiram em bases inteiramente diferentes daquelas da década de 1970. Esta retomada foi fortemente influenciada pelas transformações sociais, políticas e econômicas que se operaram no âmbito do Estado, dos atores da sociedade civil e nos enfoques analíticos dos próprios estudiosos e analistas. Foram estas mudanças gerais que influenciaram as discussões específicas sobre o tema do desenvolvimento rural, desdobrando-se em políticas governamentais direcionadas para a reforma agrária, o crédito para agricultura familiar, o apoio aos territórios rurais, o estímulo a ações afirmativas para mulheres, jovens, aposentados e negros. $\mathrm{O}$ artigo argumenta que a construção desta nova concepção do desenvolvimento rural no Brasil vem sendo fortemente influenciada por estudiosos, acadêmicos, mediadores políticos e "policy makers".

$\mathrm{O}$ artigo está dividido em quatro seções. Na primeira apresenta-se o contexto e as principais transformações econômicas e políticas que ocorreram no Brasil desde 1990 que formam o cenário que permitirá a emergência do desenvolvimento rural sob nova configuração. Neste sentido, o período histórico tem uma importância decisiva, razão pela qual a reflexão que se realiza neste texto tem como re- 
corte temporal o período da década de 1990 até os dias atuais. Na segunda seção identifica-se os principais fatores responsáveis pela retomada das discussões sobre o desenvolvimento rural no Brasil. Na terceira, apresenta-se as principais abordagens que tem sido utilizadas e referenciadas pela literatura produzida sobre desenvolvimento rural no Brasil nestes últimos quinze anos. Nas considerações finais são indicados alguns desafios ao debate sobre o desenvolvimento rural no Brasil

\section{O CONTEXTO DA DÉCADA DE 1990}

A crise econômica dos anos oitenta deixou marcas profundas e despertou uma conscientização nas principais forças políticas do Brasil de que o principal repto para o país no processo de abertura e redemocratização seria a estabilização macroeconômica, com especial atenção para o problema inflacionário. Não é objetivo descrever o quadro geral da época, mas vale lembrar que entre os fatores que fizeram com que o período de recessão fosse definido como a "década perdida" estão os problemas relacionados à crise da dívida externa com o FMI, o processo hiperinflacionário do final do governo Sarney (1985-1989), o baixo crescimento da economia e uma crescente insatisfação e frustração popular. Portanto, além de não se cumprirem as expectativas de melhoria e retomada do crescimento no período pós-ditadura, na segunda metade da década de 1980, o país mergulhou em um período de grande instabilidade econômica (Delgado, 2009).

O processo de estabilização almejado somente se iniciaria, de fato, no terceiro ano da década de 1990, com a assunção do vice-presidente Itamar Franco ao cargo de mandatário da República. Deve-se reconhecer que o processo de estabilização da economia (que passa a ostentar índices inflacionários baixos a partir de 1995) foi incrementado a partir do mandato do presidente FHC, abrindo-se espaço para o debate acerca dos condicionantes e possibilidades do desenvolvimento do país. Este contexto torna-se favorável à emergência de propostas inovadores de mudança social, entre elas, as relacionadas ao desenvolvimento rural. Além disso, não pode ser esquecido que na década de 1990, particularmente a partir de 1993-94, entram em vigor muitas das regulamentações estabelecidas pela nova constituição, que havia sido formulada em 1988. Uma delas, por exemplo, trata da descentralização política e financeira, pois os municípios passam a ser "entes federados" e, portanto, responsáveis pela execução de boa parte das políticas públicas (saúde, educação, segurança). ${ }^{1}$

Um segundo aspecto a ser considerado como parte do contexto em que emer-

\footnotetext{
${ }^{1}$ Sobre o tema da descentralização, o papel dos entes federados (estados e municípios) e o novo viés das políticas sociais há uma vasta bibliografia sendo desenvolvida no Brasil neste momento. Apenas como indicação, sugere-se a consulta aos trabalhos de Kugelmas e Sola (1999); Melo (2001) e Baiochi (2003).
} 
ge a discussão sobre o desenvolvimento rural na década de 1990, refere-se às mudanças da própria sociedade civil brasileira como um todo. Na década de 1980 as organizações e movimentos sociais que haviam sido reprimidos durante a ditadura militar retornaram ao cenário político (Sader, 1988). Contudo, a diferença desta época, é que na década de 1990 o escopo de ação dos movimentos e das organizações sociais parece ter se alterado, pois deixaram de ser apenas reivindicativos e contestatórios, passando também a ser proativos e propositivos. Acrescente-se a isto o fato de que várias organizações da sociedade civil ganharam diversidade e espessura, podendo-se citar como exemplos as organizações não-governamentais (ONGs), as associações, as cooperativas, entre outras. De uma maneira geral, pode-se dizer que a sociedade civil readquiriu e ampliou a diversidade de formas de expressão de sua complexidade política o que, sem surpresa, acaba estimulando conflitos e disputas, e às vezes revelando suas contradições.

O terceiro aspecto a ser considerado como parte do contexto em que se começa a discutir o desenvolvimento rural no Brasil na década de 1990 está relacionando com a incorporação da noção de sustentabilidade e meio ambiente. A realização da Conferência da ONU para o Meio Ambiente, em 1992, na cidade do Rio de Janeiro, trouxe consigo uma mobilização política que teve repercussões importantes sobre as instituições, o Estado e, sobretudo, os intelectuais e mediadores políti$\cos ^{2}$ Embora se possa questionar e argumentar que muitas destas repercussões não se traduziram em resultados práticos (a implementação da Agenda 21 seria um exemplo), é fato inquestionável que a partir da década de 1990, cada vez mais, as diferentes esferas de governo passam a criar instâncias de ação para tratar das questões do meio ambiente, muitas delas envolvendo regulamentações que preveem a realização de estudos de impacto e formas de controle da atividade econômica. Paulatinamente, a agenda do desenvolvimento vai incorporando múltiplas dimensões e recebendo as mais diversas adjetivações, que não carecem ser repetidas porque se transformaram em chavão (Veiga, 2006).

\section{A EMERGÊNCIA DO DEBATE SOBRE DESENVOLVIMENTO RURAL NO BRASIL}

Quais foram, então, os fatores decisivos que contribuíram para que as discussões atuais em torno do amplo tema do desenvolvimento rural fossem despertadas e ganhassem projeção, escala e, sobretudo, legitimidade? Na sua ampla maioria, estes fatores foram de fundamental importância para construção de uma nova

\footnotetext{
${ }^{2}$ Até meados da década de 1980 havia cerca de 2 mil ONGs no Brasil. Após a Eco-92 esta número cresceu assustadoramente, sendo que em 1995 eram em torno de 250 mil (Folha de São Paulo, $3 / 11 / 2004)$.
} 
percepção ou visão sobre o significado do desenvolvimento rural sendo, portanto, necessário seu conhecimento.

O primeiro, e talvez o mais importante, fator a ser destacado está relacionado com a trajetória das discussões em torno da agricultura familiar e de seu potencial como modelo social, econômico e produtivo para a sociedade brasileira. Por certo, tanto a agricultura familiar como os agricultores que hoje são assim denominados sempre existiram, e não se trata de uma novidade. Mas é mister reconhecer que foi na primeira metade da década de 1990 que esta noção se firmou como uma categoria política, sendo em seguida assimilada por estudiosos e por formuladores de políticas, o que lhe confere atualmente uma extraordinária legitimidade a tal ponto de se constituir como referência em oposição a outras noções igualmente poderosas, como a de agronegócio, por exemplo.

Tal como já indicado em outros trabalhos (Schneider, Mattei e Cazella, 2004), as razões desta legitimação estão relacionadas ao crescimento da agricultura familiar como uma categoria política, fortemente ligada à recomposição do movimento sindical dos trabalhadores rurais na década de 1990 (Favareto, 2006; Sabourin, 2007; Guanziroli, 2007). As lutas por crédito, por melhoria de preços, por formas de comercialização diferenciadas, pela implementação da regulamentação constitucional da previdência social rural, por proteção contra a desregulamentação e a abertura comercial indiscriminada (promovida no âmbito dos acordos do Mercosul), fizeram a CONTAG (Confederação Nacional dos Trabalhadores da Agricultura) aliar-se a outros movimentos emergentes, como o Departamento Nacional dos Trabalhadores Rurais (DNTR), ligado a CUT, que havia sido criado em 1988. Daí emergiram formas de mobilização e lutas que produziram grande impacto político, tais como as Jornadas Nacionais de Luta, logo a seguir transformadas no Grito da Terra Brasil, movimento anual que persiste até hoje. ${ }^{3}$

Além disso, deve-se considerar que o início da década de 1990 foi um período particularmente fértil e estimulante em que aparecerem vários estudos, livros e pesquisas que produziram um deslocamento teórico e interpretativo em relação à agricultura familiar. ${ }^{4}$ Estes trabalhos desembocaram na apresentação de uma nova tipologia dos estabelecimentos rurais brasileiros que, embora não fosse inédita, ganhou enorme projeção devido à sua vinculação ao projeto FAO/INCRA (1994).

\footnotetext{
${ }^{3}$ Essas “Jornadas” eram organizadas, no início, pela CONTAG, CUT Rural e o Movimento dos Sem Terra (MST), e contavam com a participação de outros movimentos sociais rurais. Destacam-se, também, os intensos debates, no âmbito da Comissão de Agricultura do Congresso Nacional, no período entre 1988 a 1993, quando se estabeleceu a Lei Agrícola. Esse período também foi marcado pelas grandes discussões sobre a Lei Agrária, onde as organizações dos trabalhadores rurais transformaram-se em atores importantes e com grande domínio da agenda pública nos dois temas.

${ }^{4}$ Os trabalhos de Veiga (1991), Abramoavay (1992) e a coletânea organizada por Lamarche (1993) mostraram que as formas familiares de produção não eram apenas predominantes nos países capitalistas avançados, mas também capazes de produzir excedente e desempenhar importante papel no desenvolvimento econômico destes países.
} 
Este estudo foi fundamental por ter classificado os estabelecimentos rurais brasileiros segundo a forma de uso do trabalho (familiar versus contratado ou assalariado), ter sugerindo uma tipologia que separava a agricultura familiar (consolidados, em transição e periféricos) da patronal e por ter apresentado um conjunto de sugestões de políticas agrícolas e fundiárias específicas destinadas a esta categoria social. ${ }^{5} \mathrm{Com}$ base neste trabalho, outros estudos viriam a ser desenvolvidos com o objetivo de mensurar o tamanho e o papel da agricultura familiar no Brasil, baseados no Censo Agropecuário de 1995/96 (Guaziroli et al., 2001). Estes estudos acabaram sendo importantes referências para ação do Estado e na formulação de políticas públicas para agricultura familiar e o desenvolvimento rural, tais como o PRONAF.

$\mathrm{O}$ segundo fator importante no processo de reemergência do debate sobre o desenvolvimento rural no Brasil resultou da crescente influência e ação do Estado no meio rural, que se deu tanto através das políticas para a agricultura familiar como das ações relacionadas à reforma agrária, segurança alimentar, entre outras. Sob o governo Itamar Franco e depois Fernando Henrique Cardoso, o Estado passa a legitimar as reivindicações dos movimentos sociais e a promover várias ações inéditas no espaço rural. Uma das principais ações foi a aceleração da reforma agrária, o que ocorreu pós sanção da Lei Agrária e do Rito Sumário, em 1993, sendo em seguida criada a Secretaria Especial Extraordinária de Assuntos Fundiários, que viria a ser transformada no Ministério do Desenvolvimento Agrário (MDA) em 1998. Depois, através da criação da secretaria de desenvolvimento rural (SDR-MAPA), também transferida para o MDA. Por último, deve-se registrar a criação do PRONAF (Programa Nacional de Fortalecimento da Agricultura Familiar), em 1996, que passou a ser a principal política pública destinada aos pequenos agricultores no Brasil. Desde então, seu crescimento tanto em termos de recursos como de contratos é vertiginoso e merece destaque, sobretudo a partir de 2004, quando superou a marca de um milhão e meio de contratos financiados com um orçamento que chegou a mais de nove bilhões de reais na safra 2007-2008. E o papel do Estado vem crescendo e se expandido desde meados da década de 1990, inclusive diversificando seu enfoque, agora não mais confinado apenas ao apoio aos assentamentos de reforma agrária e ao crédito para agricultura familiar, mas tratando de temas como políticas de segurança alimentar, combate às formas precárias de trabalho, regularização fundiária, apoio as populações tradicionais (quilombolas, ribeirinhos) e ações de desenvolvimento territorial.

O terceiro fator que vem fortalecendo a discussão sobre desenvolvimento rural no Brasil no período recente refere-se às mudanças no âmbito político e ideológico. Esta mudança tem um duplo sentido. Por um lado, setores das elites agrárias que até então eram contrárias às mudanças, particularmente no apoio às políticas so-

\footnotetext{
${ }^{5}$ Boa parte destas sugestões viria a ser subscrita e referenciada pelo próprio movimento sindical dos trabalhadores rurais no âmbito da elaboração do Projeto Alternativo de Desenvolvimento Rural Sustentável (Santos, 2001).
} 
ciais e de caráter compensatório viram-se forçados a mudar de posição, tal como na questão da reforma agrária. $\mathrm{O}$ outro lado desta mudança de caráter político e ideológico está no fato de que na década de 1990, lentamente, foi sendo construída uma argumentação que visava descortinar as diferenças fundamentais existentes entre o universo de produtores da agricultura brasileira. A base destes argumentos assenta-se na ideia de que existe uma oposição e uma polarização entre a forma familiar e a patronal-empresarial, cuja distinção estaria no fato de uma ser destinada mais para produção de produtos de consumo local ou para o mercado interno e a outra produziria commodities, sobretudo para exportação. Daí deriva um dualismo que, na prática, traduz-se numa acirrada disputa política e ideológica permanente entre o assim chamado agronegócio e as demais formas de produção, em geral agrupadas apressadamente em torno da agricultura familiar e do desenvolvimento rural. Esta polarização tem sido alimentada por ambos os lados e subscrita por organizações, estudiosos, mediadores e, não raro, pelos próprios formuladores de políticas (policy makers). Fruto desta polarização (na verdade, um maniqueísmo), a própria discussão sobre desenvolvimento rural ergue-se como uma alternativa e uma oposição à noção de agribusiness e agronegócio. ${ }^{6}$

O quarto e último fator importante que vem contribuindo nas discussões sobre desenvolvimento rural no Brasil está relacionado ao tema da sustentabilidade ambiental. Conforme já mencionado, o debate em torno desta questão transcende e extrapola a fronteira do espaço rural porque a própria discussão sobre a sustentabilidade é anterior à retomada do debate sobre o desenvolvimento rural. Neste caso, ocorre a confluência de dois temas que emergem no cenário social, político e intelectual ao mesmo tempo que foi a primeira metade de década de 1990. O primeiro são as críticas cada vez mais severas e consequentes ao modelo agrícola da "revolução verde", que tomam impulso a partir da metade da década de 1980. Coincidindo com estas críticas, assiste-se a uma tentativa de internalização da questão ambiental aos modelos técnico-produtivos denominados alternativos, ecológicos, orgânicos e outras nomenclaturas (Almeida, 1999; Ehlers, 1996). Paralelo a este ativismo cresce o interesse de estudiosos em converter a noção de sustentabilidade em referencial teórico e modelo de desenvolvimento (Altieri, 1987; Almeida e Navarro, 1997). ${ }^{7}$ Isto faz com que tanto o ativismo político dos ecologistas que preconizam a "agricultura alternativa" como os estudiosos do desenvolvimento sustentável acabem fornecendo contribuições importantes ao debate sobre o desenvolvimento rural, que passou a ser adjetivado de sustentável por força destes movimentos.

\footnotetext{
${ }^{6} \mathrm{O}$ fato de existirem dois Ministérios que tratam da agricultura e do meio rural no Brasil (o MDA e o Ministério da Agricultura Pecuária e Abastecimento) amplia esta controvérsia, pois não são raros os que acabam sustentando que um ministério é o da agricultura familiar e da reforma agrária (o MDA) e o outro é o ministério dos grandes proprietários identificados com o agronegócio (o MAPA).

${ }^{7}$ Sobre este tema existe uma enorme literatura no Brasil e um interesse crescente dos estudiosos, não sendo possível uma síntese apressada. Para maiores detalhes, consultar Almeida (2004).
} 


\section{SITUANDO O DEBATE TEÓRICO SOBRE O DESENVOLVIMENTO RURAL NO BRASIL}

Conforme revela a análise do contexto do debate, a discussão corrente sobre o tema do desenvolvimento rural no Brasil vem sendo fortemente influenciada pelas ações de caráter normativo e pelas políticas de intervenção do Estado. Surge daí a interrogação sobre como os formuladores das políticas elaboram sua agenda? De onde advém a inspiração do Estado e como são formulados os programas e as propostas que acabam influenciando e conduzindo as discussões sobre o desenvolvimento rural?

Existem duas possibilidades de resposta para esta indagação. Por um lado, a agenda do Estado pode refletir a demanda social e, portanto, ser fruto da pressão dos movimentos, atores, instituições e organizações do meio rural, que apresentam suas reivindicações e problemas e colocam-se na expectativa de que a tecnocracia estatal venha a apresentar propostas e soluções aos mesmos. A outra possibilidade é de que a agenda do debate e os temas do desenvolvimento rural sejam elaborados ex ante, por estudiosos, pesquisadores e acadêmicos assim como mediadores e/ou organizações que sobrevivem da elaboração de projetos e de sua interface com o Estado.

Uma análise do debate brasileiro recente sobre o tema do desenvolvimento rural permite sustentar que a formulação da agenda de ações do Estado tem sido menos influenciada pelos demandantes diretos das políticas, no caso os agricultores e as populações rurais, do que pelos estudiosos e mediadores. É claro que não se desconhece que as pressões da demanda social existem e se traduzem em efeitos práticos. Entre os exemplos mais eloquentes que poderiam arrolados estão as manifestações do movimento dos sem-terra, sobretudo as que ocorrem no âmbito do chamado "abril vermelho", e as mobilizações patrocinados pelos sindicatos de trabalhadores rurais (cuja base política, na verdade, é composta por agricultores familiares) através do "grito da terra", um evento preparatório às ações que pressionam pelo "plano safra".

Mesmo reconhecendo que, talvez, a agenda do Estado seja determinada por um misto entre as pressões dos agricultores e as inspirações captadas a partir dos mediadores, uma análise acurada de como este processo tem sido construído mostra que, no final, a balança acaba pendendo para um lado. É por isto que se sustenta que a agenda de questões que informam as políticas de desenvolvimento rural do Estado brasileiro nos últimos 15 anos tem sido fortemente permeadas pelas ideias e propostas colhidas pelos formuladores de políticas (police makers) junto aos estudiosos e mediadores, que têm exercido uma influência decisiva. Por esta razão, torna-se fundamental conhecer quem são os principais interlocutores do Estado, quais são as bases teóricas de seu pensamento e qual é seu entendimento sobre o desenvolvimento rural no Brasil.

É claro que uma análise deste tipo é de difícil aferição empírica e apoia-se, largamente, em um ponto de vista argumentativo. Isto explica e justifica por que a 
apreciação sobre as abordagens do desenvolvimento rural que se apresenta na sequência toma como referência alguns autores ou grupos de pesquisadores, deixando de lado outros que também poderiam ser mobilizados. Por esta razão, vale salientar que não se buscou fazer uma revisão de literatura, contemplando toda a obra de um ou mais autores. Sempre que possível, o objetivo central foi e de caracterizar uma abordagem sobre o tema do desenvolvimento rural.

\section{Instituições, inovação e sutentabilidade}

A perspectiva do desenvolvimento rural que encontra guarida nos trabalhos de José Eli da Veiga e Ricardo Abramovay constitui-se em uma proposta fértil e de amplo escopo temático e teórico. Ao longo de vários anos de pesquisa na seara dos temas rurais, a trajetória destes pesquisadores da USP vem se articulando em torno de uma matriz multidisciplinar em que se destacam a economia, a ecologia e a sociologia econômica. Em face de sua trajetória e capacidade formadora de quadros, as perspectivas sustentadas por estes autores refletem-se nos trabalhos de vários seguidores, muitos dos quais espalhados por instituições da sociedade civil e mesmo instâncias de governo.

Para ambos, a valorização da agricultura familiar e o reconhecimento de seu potencial dinamizador das economias locais talvez seja o principal ponto de consenso. Em maior ou menor medida, sustentam o argumento de que a capacidade de inovação dos agricultores familiares e sua interação com as instituições locais são fundamentais para que possam ampliar a geração e agregação de valor, assim como reduzir custos de transação e estimular economias de escopo. O fato de terem realizado estudos sobre as condições e potencialidades da agricultura familiar em sociedades capitalistas avançadas parece ter sido o ponto de partida para suas formulações sobre o desenvolvimento rural. Em geral, consideram os agricultores familiares como "empreendedores", sendo sua capacidade de inovação uma característica herdada de seu passado camponês. Mas camponeses e agricultores são distinguidos sendo o traço diferenciador a integração aos mercados e sua reprodução em um ambiente que estimula o agricultor a virar produtor de mercadorias. Como pequenos proprietários, donos de seus meios de produção, os autores sustentam que a reprodução dos agricultores familiares depende de sua capacidade de fazer escolhas e desenvolver habilidades em face aos desafios que lhe são colocados pelo ambiente social e econômico em que vivem. Neste ambiente, são compelidos a inovar constantemente (através do treadmill tecnológico e da interação territorial) e a se tornarem pluriativos.

Os autores desenvolvem o argumento de que a capacidade empreendedora e inovadora dos agricultores familiares é a responsável pela diversificação social e produtiva dos territórios rurais em que vivem. A partir deste enfoque seus trabalhos passam a dialogar com as discussões sobre as dinâmicas territoriais do desenvolvimento do espaço rural. Em decorrência, ambos estudiosos tornaram-se fontes de 
influência da introdução da noção de desenvolvimento territorial no Brasil (que foi incorporada as políticas públicas nos anos recentes), em geral fortemente assentada nos seus diálogos com a bibliografia européia, particularmente francesa (a noção de contratos ou projetos territoriais, a ideia de distritos e de ambientes de inovação, entre outras). Alguns trabalhos de Veiga indicam que os territórios mais propícios ao processo de inovação seriam aqueles em que as economias locais são capazes de gerar uma demanda agregada por produtos e serviços, que é estimulada pela circulação em nível local da riqueza acumulada e ativada pelo empreendendorismo, formando um círculo virtuoso (ou "manchas") de desenvolvimento. Além disso, o autor problematizou enfaticamente a natureza territorial do próprio espaço rural, sustentando que "o rural brasileiro é muito maior" do que indicam as análises setoriais derivadas do serviço censitário oficial (Veiga, 2002). Abramovay, numa perspectiva mais sociológica, recorreu à literatura sobre capital social, especialmente, a sua acepção à la Putnam, para discorrer sobre os fatores que geram cooperação, reciprocidade e solidariedade, que seriam elementos fundamentais para ativar as economias de proximidades e relativizar os conflitos locais em torno de uma "ideia guia". Derivam daí seus trabalhos sobre o papel do capital social no desenvolvimento dos territórios rurais e estudos sobre as "economias de proximidade", em que procura revelar que determinados ambientes são propícios à inovação porque neles existe uma tradição histórica de cooperação que gera capacidade de mobilização em torno de um projeto ou uma ideia-guia (Abramovay, 2003, 2006).

Embora percorrendo agendas de pesquisa próprias, ambos autores compartilham ainda um consenso em relação ao papel das instituições no meio rural. Enquanto nos trabalhos de Veiga as instituições aparecem associadas ao próprio Estado (empresas públicas, políticas governamentais) ou a organismos paraestatais (consórcios intermunicipais, agências de desenvolvimento, universidades), os estudos de Abramovay vão focalizar as organizações dos agricultores, as suas formas de cooperação e as regras e normas tácitas (o capital social) existentes nos territórios. Nos dois casos, ressalta-se a importância e o papel das instituições na formatação de um ambiente institucional cujo papel seria o de reduzir incertezas e riscos, criando formas de governança e gestão fundamentais para redução de custos de transação. Por conta dessas análises, e de sua inegável capacidade de traduzir referências analíticas em um ideário programático, ambos autores mantêm relações estreitas com instituições que atuam no campo do desenvolvimento rural, em geral atuando em estudos de avaliação e consultorias que influenciam as agendas políticas de governos e organizações.

\section{O novo rural brasileiro: atividades não-agrícolas e políticas compensatórias}

$\mathrm{O}$ arcabouço analítico e conceitual sobre o desenvolvimento rural que deriva dos trabalhos e pesquisas realizados no âmbito do Projeto Rurbano constitui-se na segunda vertente a ser analisada. De uma maneira geral, os trabalhos deste grupo 
de pesquisa tornaram-se reconhecidos no âmbito acadêmico e político-institucional no Brasil desde o final da década de 1990 por terem demonstrado que o meio rural do final do século XX, assim como alhures, já não podia ser considerado exclusivamente agrícola. Mobilizando mais de quatro dezenas de pesquisadores universitários (25 com título de doutor) de onze estados da federação, de vinte diferentes instituições e com um portofólio de mais de vinte subprojetos, o projeto criado e coordenado pelo professor José Graziano da Silva demonstra desde sua criação, em 1996, até os dias atuais, vitalidade e capacidade de intervenção no mais diversos espaços.

Tal como indicado por Graziano da Silva (2001) e Graziano da Silva; Del Grossi e Campanhola (2002), o surgimento do novo rural brasileiro decorre do próprio processo de modernização conservadora da base tecnológica da agropecuária. Quando este processo se completa, no final da década de 1980, especialmente nas regiões centro e sul do Brasil, emerge no meio rural uma nova conformação econômica e demográfica que possui como característica fundamental a redução crescente das diferenças entre o urbano e o rural, especialmente no que se refere ao mercado de trabalho, devido ao crescimento da população ocupada em atividades não agrícolas. O rural deixa de ser "sinônimo de atraso" e se desconecta da agricultura, que passa a ser apenas uma de suas atividades. Segundo Graziano da Silva (1999), a erosão das diferenças entre o rural e o urbano leva ao aparecimento de um continuum entre ambos, que pode ser captado pela expressão rurbanização, de autoria de Gilberto Freire, mas que vai servir para descrever a etapa atual do processo de mudança espacial e demográfica.

Esse novo rural (ou o processo de rurbanização) seria composto, basicamente, por três grupos de atividades, quais sejam: uma agropecuária moderna (agronegócio) baseada em commodieties e intimamente ligada as agroindústrias; um conjunto de atividades não agrícolas ligadas à moradia, ao lazer e a várias atividades industriais e de prestação de serviços e, por último, um conjunto de novas atividades agropecuárias, impulsionadas por nichos de mercado. Além desta faceta moderna, o lado atrasado do rural persistiria por meio da manutenção da pobreza e da vulnerabilidade de ampla gama da população, identificada com o grupo social que Graziano da Silva denominou de "sem-sem", que seria formado pelos excluídos e desorganizados que, além de não terem terra, emprego, educação, saúde e renda, não teriam sequer uma organização social que os mobilizasse (Graziano da Silva, 2001). O semblante deste novo rural seriam a famílias pluriativas, que são aquelas que combinam atividades agrícolas e não-agrícolas e promovem a integração intersetorial (agricultura com comércio e serviços) e interespacial (rural com urbano).

Do ponto de vista teórico, esta interpretação de Graziano não deixa de afinar-se com seus trabalhos anteriores, em que sustentava que a modernização conservadora da agricultura brasileira teria resolvido o problema agrícola colocado pelo modelo capitalista de desenvolvimento na década de 1950, quando se produziu uma fissura entre a questão agrícola e a agrária. A solução da questão agrícola 
teria se dado pelo incremento tecnológico e produtivo da agropecuária nacional que, uma vez modernizada, teria eliminado os problemas da oferta de produtos. $\mathrm{Na}$ opinião de Graziano da Silva, restaria ser resolvido o problema agrário, que seria fundamentalmente de natureza social e demográfica, dado o excedente populacional (a tese de Inácio Rangel) ainda existente no campo e a incapacidade do setor agrícola moderno (agronegócio) de promover sua absorção através dos processos de produção.

Com base na excepcional capacidade dos pesquisadores do Projeto Rurbano de produzir dados e estatísticas, especialmente a partir de uma metodologia de uso dos dados da PNAD (Pesquisa Nacional de Amostra por Domicílios), não foi difícil demonstrar que desde a década de 1980 ocorria no Brasil uma queda constante da população economicamente ativa ocupada nas atividades agrícolas. Portanto, à medida que o progresso tecnológico avança na agricultura sob o capitalismo, é inútil esperar pela elevação dos níveis de emprego e ocupação. Neste sentido, a solução viável para o problema agrário historicamente remanescente poderia se dar pela geração de oportunidades de trabalho e renda em atividades não agrícolas (já que o setor agrícola modernizado é poupador de força de trabalho) ou, quando isto não é possível, acionar políticas sociais compensatórias, incluindo-se aí a reforma agrária seletiva (a "reforminha"), as ações de combate à fome (donde deriva o programa que mais adiante viria a ser o Projeto Fome Zero) e de segurança alimen$\operatorname{tar}$ (apoio as formas de comercialização dos pequenos produtores), entre outras.

Este conjunto de políticas sociais e compensatórias, destinadas a amplos contingentes da população rural que vivem em condições de pobreza e vulnerabilidade social (particularmente na região semi-árida do Nordeste), deveria ser somado às políticas para o novo rural brasileiro, que incluem políticas de habitação, de turismo rural, valorização das amenidades, de regularização das relações trabalhistas e de urbanização do rural (serviços, infraestrutura e planejamento), entre outras. Em seu conjunto, a convergência das políticas para o "novo" rural e para o rural "precário e atrasado" comporiam o quadro das ações de desenvolvimento rural. De fato, quando foi ministro do governo Lula (2003-2005), Graziano da Silva procurou implementar várias destas políticas, sendo que algumas persistem até os dias atuais, tais como programa Fome Zero.

\section{A “força da tradição" e os limites históricos e sociais ao desenvolvimento rural}

Uma outra vertente de estudos sobre o desenvolvimento rural a ser caracterizada edifica sua agenda temática em torno dos condicionantes e das potencialidades dos processos de mudança social no meio rural do Brasil a partir da análise da tradição política de tipo tradicional e patriarcal, que obstaculizaria não só as transformações estruturais mas, fundamentalmente, as mudanças de natureza sociocultural. Embora seja uma vertente de pensamento que não se organiza em torno de uma agenda de pesquisa comum, seus expoentes reiteram que há limites e dificuldades 
que remetem à própria formação do tecido social brasileiro que impediriam mudanças mais gerais nas instituições, nas organizações sociais e, sobretudo, no Estado.

Os temas tratados neste vertente analítica tem a ver como o estudo do clientelismo, do patriarcalismo e de comportamentos e práticas sociais e políticas baseadas naquilo que Max Weber denominou de formas de dominação assentadas na pessoa (carismática) e nos estamentos sociais (tradicional). Nesta perspectiva, esposada por sociólogos e cientistas políticos, as condições e possibilidades do desenvolvimento rural e a alteração das condições de vida das populações em situação de vulnerabilidade, esbarra em mecanismos de dominação social e cultural que são construídos historicamente por elites locais para legitimar seu poder e manter os privilégios que sustentam suas posições. $\mathrm{Na}$ opinião de estudiosos como José de Souza Martins, Zander Navarro, entre outros, nos espaços rurais do Brasil a mudança prioritária a ser promovida não passaria apenas pela promoção do acesso aos ativos ou a recursos materiais e financeiros, tais como a terra, água, obras de infraestrutura ou crédito para financiar plantio e comercialização.

Refletindo realidades diversas, estes autores ressaltam a necessidade da promoção de processos radicais de democratização, que pudessem libertar os indivíduos e grupos sociais da tutela e controle exercido pelas elites e pelos mediadores (agentes da Igreja, do Estado, dos partidos políticos, dos movimentos sociais). Sustentam, basicamente, que as próprias populações rurais deveriam organizar instâncias de gestão cuja institucionalização e legitimação passaria pelo Estado em uma via de mão dupla. De um lado, através da concessão de recursos (financiamentos, infrestrutura) e por meio do reconhecimento de direitos (cidadania, acesso à terra) e, de outro lado, por meio da exigência de contrapartidas que se materializariam em melhorias nos indicadores de qualidade de vida e bem-estar social (escolarização, por exemplo). Estudos como os de Navarro (1999, 2002); Martins $(1999,2003)$ e Fox (1990) indicam que os processos de desenvolvimento podem e devem contribuir, efetivamente, para estimular a "emancipação social”, criar mecanismos de responsabilização (accountability) e, desse modo, promover a democratização da sociedade.

Em sua vasta obra, José de Souza Martins indica exaustivamente os problemas decorrentes da inadequada compreensão que, em geral, os mediadores e os formuladores de políticas (além dos intelectuais) têm em relação aos seus beneficiários, no caso as populações rurais. Segundo Martins (1981), a história do Brasil está repleta de exemplos de práticas cuja proposta de "ajudar os outros" acaba criando formas de dominação e controle desses outros. Esta trajetória vai desde o clientelismo e o patriarcalismo (tão bem expressos na ideia da prestação do favor) do período pré-republicano, passa pelo populismo do Estado Novo, até chegar ao período contemporâneo, quando assume a feição social-comunitarista que orienta a ideologia dos partidos de esquerda, bem como as organizações ligadas à Igreja, tal como a Comissão Pastoral da Terra (CPT). Em seus trabalhos mais recentes, Martins procurou mostrar a face contraditória da sociedade brasileira que, malgrado tenha se moder- 
nizado econômica e tecnologicamente, foi capaz de manter formas de dominação e subordinação conservadoras baseadas no clientelismo. Aliás, este é um tema central em seus estudos sobre a "questão agrária" no Brasil (especialmente os focalizados na região amazônica), em que sustenta que a superação do bloqueio que a propriedade da terra representava para o desenvolvimento do capitalismo teria ocorrido através da conversão da posse da terra em "renda capitalizada", transformando os latifundiários em capitalistas. Este processo conservador (no sentido de que não implicou em rupturas ou em um processo revolucionário) teria sido iniciado com a Lei de Terras, em 1850, e se consolidado durante a ditadura militar (1964-1984), quando o Estado se incumbiu de financiar este processo conservador de modernização. Mas, "o poder do atraso" e suas metamorfoses, segundo Martins, atingiriam também outras esferas da sociedade, tal como a tecnocracia estatal, os partidos políticos e as instituições, tornando-se uma prática política corrente. Em seus estudos sobre os movimentos sociais e as organizações, Martins lança mão desta perspectiva para analisar os modos de controle e as formas de dominação presentes no movimento dos sem-terra (MST), na comissão pastoral da terra (CPT, ligada à Igreja Católica) e nos assentamentos de reforma agrária.

Embora não sob o mesmo enfoque, os trabalhos de Navarro também revelam as dificuldades e os limites dos processos de transformação em uma sociedade marcadamente conservadora. Centrando seu foco de estudos sobre as possibilidades de "emancipação social", geradas a partir da emergência dos movimentos sociais da década de 1980, seus trabalhos recentes são marcados por um desencantamento e ceticismo em relação ao seu potencial para o desenvolvimento rural. Entre seus argumentos sustenta que os atores sociais rurais, sejam eles movimentos sociais ou organizações formais, tais como os sindicatos e as ONGs, seriam politicamente frágeis, não estariam preparados e nem sempre interessados em promover mudanças mais profundas. Sua fragilidade decorreria das bases sociais em que se apóiam, cuja característica seria a instabilidade (sobretudo em relação a recursos financeiros) e a subordinação a agentes externos (em geral o Estado ou às elites políticas locais). A falta de preparo adviria de deficiências substantivas relacionadas à qualidade de seus quadros técnicos, às vezes refletidas em propostas e projetos de pouco potencial transformador (como exemplos, problematiza os formatos tecnológicos que têm sido difundidos nos assentamentos de reforma agrária e pelas ONGs). Mas suas críticas mais contundentes voltam-se ao reduzido interesse dos atores sociais que surgiram no período pós-ditadura militar em promover mudanças efetivas que estimulem a democratização real da sociedade. Navarro sustenta que o caráter revolucionário e transformador dos movimentos sociais (assim como de outros atores) foi lentamente esvaziado e confinado a um discurso retórico e a uma ideologia ultrapassada que estariam em contradição com as próprias práticas que vigoram no interior destas organizações, que seriam assentadas em formas de dominação e controle clientelistas e pouco democráticas. 


\section{Um enfoque agroalimentar para o desenvolvimento rural}

A quarta abordagem a ser focalizada possui uma relação fluída e pouco identificada com as questões mais gerais do desenvolvimento rural. Talvez alguns de seus autores até mesmo nem se coloquem esta questão ou qualquer preocupação com o tema do desenvolvimento rural per se. Em linhas gerais, trata-se de uma vertente de estudos que focaliza o agronegócio e as cadeias agroalimentares sob uma perspectiva que, em geral, não é aquela que subscreve a teoria econômica convencional (o mainstream). São autores que analisam as formas de integração dos pequenos produtores (embora não apenas destes) nas cadeias agroindustriais ou agroalimentares, revelando uma preocupação consequente com os aspectos sociais deste processo. Ou seja, não se trata apenas de examinar as formas de gestão, administração, tomada de decisão, formas de inovação, acesso a mercados e comercialização, que são usualmente os temas de interesse dos estudiosos do agronegócio, mas de entender em que condições os pequenos produtores e suas organizações podem fazer frente aos desafios colocados pela forma atual como o capitalismo opera na agricultura e na produção de alimentos. Por outro lado, trata-se de um conjunto de analistas (em geral economistas, administradores e agrônomos), cujos trabalhos começaram a aparecer a partir da década de 1990, que oferecem uma interpretação alternativa aos estudos dos anos de 1980 que estavam demasiadamente presos à ideia de que a integração dos agricultores às agroindústrias (ou complexos agroindustriais, CAIs, como eram então denominados) os levaria, fatalmente, à subordinação e a perda de sua autonomia.

É claro que sob este "guarda-chuva"corre-se o risco de incluir perspectivas analíticas e interpretativas que nada tem a ver com o tema do desenvolvimento rural. A questão mais geral que perpassa os trabalhos de diversos autores desta corrente e mesmo suas abordagens teóricas está no diagnóstico, quase consensual, de que na fase atual do capitalismo, as possibilidades de sobrevivência e reprodução social dos agricultores familiares enquanto produtores de alimentos, fibras e matérias-primas depende, fundamentalmente, de sua capacidade de inserção em um ambiente em que sejam capazes de inovar (progresso técnico), adquirir um domínio relativo sobre os mercados e desenvolver formas de gestão e planejamento da propriedade. Outro ponto de consenso entre os autores desta abordagem é o fato de que, em geral, analisam um tipo de agricultura familiar mais "capitalizada", com acesso aos mercados e às tecnologias mais modernas, não raro localizada nas regiões dinâmicas das economias rurais.

Como não é possível (e tampouco este é o objetivo) revisar toda a literatura que trabalha com estes temas, toma-se como indicação e referência os trabalhos de Wilkinson $(1999,2000,2003)$ e os autores das coletâneas organizadas por Lima e Wilkinson (2002) e Souza Filho e Batalha (2005). Talvez os trabalhos de Wilkinson possam ilustrar algumas das questões e desafios que esta perspectiva lança sobre a temática do desenvolvimento rural. O que Wilkinson chamou de "enfoque agroin- 
dustrial" ressalta a importância de se compreender quais são as condições e possibilidades da agricultura familiar vir a desempenhar um papel importante na produção agroalimentar em um momento histórico em que o capitalismo está passando da fase fordista para um regime de produção e consumo flexíveis. Nesta nova etapa, a "vontade do consumidor" (Wilkinson, 2000) passará a orientar a organização dos processos de produção e o tipo de produto a ser produzido. Além disso, como o problema da oferta de alimentos (capacidade instalada de produção e know-how) seria uma questão quase superada (com exceção nos países e regiões pobres), os novos desafios da produção agroalimentar se voltariam para a segurança dos alimentos (sanidade) e a busca de formas sustentáveis (impactos ambientais) e socialmente justas de produção (observância às questões éticas, morais e humanitária). Daí emerge uma discussão que, aos poucos, vai inclusive superar a noção de cadeia de produção e introduzir em seu lugar a ideia de redes que, segundo Wilkinson (2006), é uma noção útil e adequada para dar conta dos aspectos sociais e técnicos da produção.

O desafio para a agricultura familiar consistiria na melhoria de sua capacidade de interação social e inserção em mercados locais ou non-standards (merenda escolar, programas sociais) em um contexto de "economia da qualidade". A economia da qualidade refere-se às múltiplas formas de construção social (embededdness) da percepção do que é qualidade, que pode estar na oferta de produtos tradicionais, artesanais ou regionais. Neste cenário, os agricultores familiares precisariam desenvolver habilidades para construir os novos mercados, saber "ler as tendências e os gostos dos consumidores", ser capaz de organizar redes sociotécnicas (de tipo fair trade ou solidárias) e cadeias curtas de produção (short supply agrifood chains) que permitam atender a demanda.

A capacidade da agricultura familiar para atender as demandas flexíveis de mercados cada vez mais segmentados e exigentes (nichos) adviria de sua grande capacidade de inovação através da experimentação (learning-by-doing) e aprendizagem coletiva por conhecimento tácito. Como na agricultura a produção é largamente dependente da natureza e se assenta em "deseconomias de escala”, somente os próprios produtores-trabalhadores conseguem fazer ajustes constantes nos processos de produção. Este conhecimento acaba se difundindo por meio de redes de sociabilidade (amizade, vizinhança, compadrio) e afeta todo o sistema produtivo local, o que gera formas de inovação por aprendizagem coletiva e uma competitividade que se reflete em nível territorial. Embora estas sejam as potencialidades, existem também os riscos e os limites. Entre eles, Wilkinson destaca, em primeiro lugar, o baixo grau de escolaridade dos agricultores. Mas outras barreiras também são importantes, como por exemplo, a restrita capacidade de absorção dos mercados locais dos excedentes produzidos ou os limites de escala exigidos pelas redes convencionais de comercialização (grandes redes de supermercados e comércio atacadista), que cobram altos preços de entrada para os produtos dos pequenos agricultores. Um outro obstáculo, ainda, refere-se à garantia dos direitos de propriedade $\mathrm{e}$ 
à apropriação dos resultados gerados, pois muitos agricultores desconhecem as formas contratuais de negociação e ficam vulneráveis a todo tipo de risco.

\section{ALGUMAS CONSIDERAÇÕES FINAIS}

A partir da apresentação do contexto social, político e intelectual em que emergiu o debate sobre o desenvolvimento rural no Brasil, este ensaio procurou mostrar quais foram os principais fatores que contribuíram para que a discussão do tema ganhasse legitimidade. Neste processo, o papel do Estado e das políticas públicas que focalizam os agricultores familiares e a reforma agrária tiveram um papel decisivo, pois foi através delas que se instaurou um debate entre estudiosos e pesquisadores que passaram a alimentar o próprio tema do desenvolvimento rural. Mas também se indicou que a discussão sobre desenvolvimento rural no Brasil está impregnada de um sentido político e ideológico que se alimenta e fortalece à medida que a polarização entre os defensores do agronegócio e da agricultura familiar (embora não só esta) ganham destaque e legitimidade. Outro fator que contribuiu com a emergência da discussão sobre desenvolvimento rural foi o modo como as questões ambientais e aquelas relacionadas com a sustentabilidade foram incorporadas ao tema mais geral do desenvolvimento.

O trabalho também procurou demonstrar que o debate atual sobre o desenvolvimento rural no Brasil é amplamente tributário das contribuições dos estudiosos e mediadores, mais até do que a própria demanda dos atores e das organizações sociais e políticas do meio rural. Portanto, a porta de entrada das discussões sobre o desenvolvimento rural no Brasil nos últimos 15 anos foi fortemente influenciado pelo Estado e suas relações com os mediadores e estudiosos. Isto não significa que os atores, as organizações e as instituições formais que atuam no meio rural não tenham interagido ou pressionado o Estado. Também não representa uma novidade ou uma situação sui generis do Brasil em relação ao que se passa em outras situações e contextos, como é o caso, em particular, da Europa e da sua política para agricultura e o meio rural.

O que procurou-se demonstrar é que o debate sobre o desenvolvimento rural no Brasil emergiu e se consolidou como uma questão e um tema de interesse à medida que os estudiosos e mediadores foram produzindo interpretações sobre os processos sociais transcorridos desde o princípio da década de 1990. Em geral, foram estes estudos e documentos que serviram aos agentes, mediadores e formuladores de políticas como inspiração para elaboração de formas de intervenção e planejamento. A demanda social e política propriamente dita raramente conseguiu pautar o debate (talvez com a exceção dos signatários da reforma agrária), embora tenha entrado no processo como uma síntese do pensamento, das formulações produzidas pelos estudiosos e mediadores sobre elas.

Em relação às principais abordagens teóricas que discutem o desenvolvimento 
rural no Brasil buscou-se salientar os temas e as perspectivas analíticas e interpretativas que oferecem. De uma forma geral, adotando-se uma visão de conjunto, foi possível perceber que a existência de algumas convergências e consensos entre as propostas analisadas, ainda que nem todas tenham sido exaustivamente exploradas na exposição. Primeiro, os estudiosos parecem concordar que a usual redução do espaço rural às atividades agropecuárias perdeu sentido na atualidade, colocando-se o desafio de pensar as interfaces e os atributos que caracterizam o espaço e seu conteúdo como um todo. Segundo, há um relativo consenso sobre a dimensão multidimensional da sustentabilidade do desenvolvimento, assim como em relação ao papel da agricultura familiar e das formas heterogêneas de sua inserção na dinâmica da economia capitalista. Terceiro, mesmo que de forma difusa, as abordagens parecem concordar que no Brasil o foco das ações do desenvolvimento rural deve ser o combate à pobreza e às múltiplas vulnerabilidades das populações rurais.

Mas uma apreciação comparativa permite constatar que os estudiosos raramente coincidem em relação às perspectivas e tendências para o meio rural e menos ainda no que se refere às estratégias de intervenção a ser seguidas. Ainda que as divergências possam ser consideradas como um sinal de vitalidade do debate, a avaliação que se faz é que uma vez instaurado, o passo seguinte seria a elaboração de definições mais claras em relação ao seu escopo e, sobretudo, a exposição de um corpus de conceitos, metodologias e experiências empíricas que possam servir de referência e serem replicadas. Mas é aí que se esbarra em uma grande dificuldade. Até o momento, conforme se afirmou no ensaio, sob a noção de desenvolvimento rural, o que parece existir é uma discussão sobre temas e questões que afetam as populações rurais, a agricultura e o espaço, que são submetidos à análise, reflexão e à avaliação pelos estudiosos a partir de demandas externas, em geral formuladas pelo Estado, pelos mediadores e outros organismos. ${ }^{8}$

Acredita-se que os estudos sobre o desenvolvimento rural no Brasil precisam definir a sua própria agenda temática, sobretudo restringir sua amplitude e generalidade. Da forma como está colocada, torna-se difícil reconhecer qual é sua agenda de pesquisa e definir o que são, precipuamente, estudos sobre desenvolvimento rural. Talvez o passo inicial pudesse ser a busca de uma maior emancipação em relação aos temas que são importados a partir das ações do Estado e das políticas públicas. Isto não quer dizer que vá desaparecer ou que tenha que deixar de existir esta interface. Não obstante, se os estudos sobre o desenvolvimento rural pretendem ser razoavelmente orientados pela perspectiva dos processos de mudança social será preciso que busquem manter uma interface crítica e construtiva em relação aos seus interlocutores, notadamente o Estado e suas políticas para o meio rural.

Como uma pista para trabalhos futuros, acredita-se que existem possibilidades e lacunas inexploradas pelos estudos sobre o desenvolvimento rural no Brasil que

\footnotetext{
${ }^{8}$ Os vários artigos que compõem o "Dossiê Desenvolvimento Rural”, publicado pela Revista Estudos Avançados da USP, em 2001, indica esta tendência.
} 
se encontram na necessidade de analisar mais aprofundadamente o papel dos agricultores e demais atores do meio rural nos processos de mudança social. Falta conhecer, por exemplo, como os agricultores e suas famílias reagem às mudanças tecnológicas e a uma maior interação com o mercado e os demais atores da sociedade. Em que medida estas forças externas reconfiguram as relações intrafamiliares de poder, de trabalho e de gênero. De que modo, afinal, os próprios agricultores reagem e quais são os recursos e as estratégias que utilizam. Embora muitas destas questões já tenham sido tratadas de um modo ou outro, ainda não foi conferida suficiente atenção e tampouco se dispõe de referências teóricas consistentes sobre estes enfoques.

Deste modo, talvez se pudesse aproximar o debate brasileiro da literatura internacional corrente sobre o desenvolvimento rural, que tem apontado para a necessidade de se compreender o ponto de vista dos agricultores e dos atores sociais no processo de mudança social. Fica, portanto, como desafio aos estudos sobre desenvolvimento rural no Brasil, ir além da análise e interpretação das transformações que ocorrem nas formas de produção, nas tecnologias, nas instituições e na crescente interação com os mercados. Este esforço é importante, mas será parcial e incompleto se os estudos e pesquisas não forem capazes de mostrar em que medida estas dimensões afetam as relações com o espaço e o meio ambiente, se contribuem ou não para melhoria das condições de vida da população rural fazendo, enfim, com que o desenvolvimento seja, efetivamente, um processo de mudança social.

\section{REFERÊNCIAS BIBLIOGRÁFICAS}

ABRAMOVAY, R. (2004) "Entre Deus e o diabo: mercados e interação humana nas ciências sociais”, Tempo Social, 16 (2):. 35-64.

ABRAMOVAY, R. (2003) O Futuro das Regiões Rurais. Porto Alegre: Ed. UFRGS, Porto Alegre.

ABRAMOVAY, R. (2006) "Para una teoría de los estudios territoriales", in MANZANAL, M.; NEIMAN, G. e LATTUADA, M.(orgs.) Desarrollo rural: organizaciones, instituciones y territorios. Buenos Aires: Ciccus.

ABRAMOVAY, R. (1992) Paradigmas do capitalismo agrário em questão. São Paulo: Hucitec.

ALMEIDA, J. (1999) A construção social de uma nova agricultura. Porto Alegre: Editora da UFRGS.

ALMEIDA, J. (2004) “Agroecologia: nova ciência, alternativa técnico-produtiva ou movimento social?” In: RUSCHEINSKY, A. (org.), Sustentabilidade: uma paixão em movimento. Porto Alegre: Editora Sulina.

ALMEIDA, J. e NAVARRO, Z. (1997) Reconstruindo a agricultura: ideias e ideais na perspectiva do desenvolvimento rural sustentável. Porto Alegre, Editora da UFRGS.

ALTIERI, M. (1987) Agroecology: the scientific basis of alternative agriculture. Boulder, Westview Press.

BAIOCCHI, G. (2003) "Inequality and innovation: decentralization as an opportunity structure in Brazil”. University of Pittsburgh, Draft Revised March, 2003.

DEL GROSSI, M.; GRAZIANO DA SILVA, J. e CAMPANHOLA, C. (2002) "O que há de realmente novo no rural brasileiro?” Cadernos de Ciência e Tecnologia, Brasília, 19 (1): 2002.

DELGADO, N.G. (2009) “Papel e lugar do rural no desenvolvimento nacional”. Brasília, IICA-MDA-CONDRAF, Texto para Discussão. 
EHLERS, E. (1996) Agricultura sustentável: origens e perspectivas de um novo paradigma. São Paulo: Livros da Terra.

FAO/INCRA (1994) Diretrizes de Política Agrária e Desenvolvimento Sustentável. Brasília, Versão Resumida do Relatório Final do Projeto UTF/BRA/036.

FAVARETO, A. (2006) "Agricultores, trabalhadores: os trinta anos do novo sindicalismo rural no Brasil”, Revista Brasileira de Ciências Sociais, 21 (62).

FOX, J. (1990) "Democratic rural development: leadership accountability in regional peasant organizations", Development and Change, 23 (2).

GRAZIANO DA SILVA, J. (1999) O novo rural brasileiro. Campinas, UNICAMP, Instituto de Economia, 1999. (Coleção Pesquisas, 1);

GRAZIANO DA SILVA, J. (2001) “Quem precisa de uma estratégia de desenvolvimento”. Textos Para Discussão Nead, Campinas/SP, v. 2: 5-52.

GUANZIROLI, C.E. et.alii. (2001) "Novo retrato da agricultura familiar: O Brasil redescoberto". In: GUANZIROLI, C.E. et.ali. Agricultura familiar e reforma agrária no século XXI. Rio de Janeiro, Garamond;

GUANZIROLI, C.E. (2007) "PRONAF dez anos depois: resultados e perspectivas para o desenvolvimento rural', Revista de Economia e Sociologia Rural (SOBER), 45 (2): 301-328.

IPEA (2007) Políticas sociais - acompanhamento e análise. Brasília, IPEA, Edição especial n ${ }^{\circ} 13$

KUGELMAS, E.; SOLA, L. (1999) "Descentralização/recentralização: a dinâmica do regime federativo no Brasil na década de 1990", Revista Tempo Social, 11.

LAMARCHE, H., coord. (1993) A agricultura familiar I: uma realidade multiforme. Campinas: Editora da UNICAMP.

LEITE, S.P. (2005) "Estado, padrão de desenvolvimento e agricultura: o caso brasileiro", Estudos Sociedade e Agricultura, 13(2): 280-332.

MARTINS, J.S. (1999) O poder do atraso. Ensaios de sociologia da história lenta. São Paulo: Hucitec, $2^{\mathrm{a}}$ Edição.

MARTINS, J.S. (2003) O Sujeito oculto. Ordem e transgressão na reforma agrária. Porto Alegre: Ed. UFRGS.

MARTINS, J.S. (1981) Os camponeses e a política. As lutas sociais no campo e seu lugar no processo político, Rio de Janeiro: Vozes, $1^{\text {a }}$ Edição.

MARTINS, J.S. (2000) Reforma agrária: o impossivel diálogo. São Paulo: Editora USP.

MDA/CONDRAF. (2006) Diretrizes para o Desenvolvimento Rural Sustentável. Brasília-DF, MDA, Série Documentos n ${ }^{\circ}$ 03, junho.

MELO, M.A.(2001) “A política da ação regulatória: responsabilização, credibilidade e delegação”, Revista Brasileira de Ciências Sociais, 16 (46): 55-69.

NAVARRO, Z. (2001) "Desenvolvimento rural no Brasil: os limites do passado e os caminhos do futuro", Revista Estudos Avançados, 16 (44): 83-100.

NAVARRO, Z. (1999) Manejo de recursos naturais e desenvolvimento rural: um estudo comparativo em quatro estados brasileiros (lições e desafios). Relatório ao Banco Mundial.

NAVARRO, Z. (2002) "Mobilização sem emancipação: as lutas sociais dos sem terra no Brasil", In SANTOS, B.S., org. Produzir para Viver: Os Caminhos da Produção Não Capitalista. São Paulo: Civilização Brasileira.

SABOURIN, E. (2007) "Que política pública para a agricultura familiar no segundo governo Lula?" Sociedade e Estado, 22 (3): 715-751.

SADER, E. (1988) Quando novos personagens entraram em cena. Rio de Janeiro: Paz e Terra.

SANTOS, M.J. (2001) "Projeto alternativo de desenvolvimento rural sustentável”, Revista Estudos Avançados, 16 (44).

SOUZA FILHO, H.M e BATALHA, M.O., org. (2005) Gestão Integrada da agricultura familiar. São Carlos-SP: Editora da UFSCAR.

VEIGA, J. E. (2001) “O Brasil rural precisa de uma estratégia de desenvolvimento”. Brasília- DF, NE$\mathrm{AD}$, Texto para Discussão n ${ }^{\circ} 01$.

VEIGA, J. E. (1991) O desenvolvimento agrícola: uma visão histórica. São Paulo: Hucitec. 
VEIGA, J.E. (2002) Cidades Imaginárias: o Brasil é menos urbano do que se calcula. Campinas-SP: Editora Autores Associados.

VEIGA, J.E. (2006) Desenvolvimento sustentável. O desafio do Século XXI. São Paulo: Garamond.

WILKINSON, J. (2003) "A agricultura familiar ante o novo padrão de competitividade do sistema alimentar na América Latina", Estudos Sociedade e Agricultura, n.21.

WILKINSON, J. (1999) "A contribuição da teoria francesa das convenções para os estudos agroalimentares", Ensaios FEE, 20 (2): 64-80.

WILKINSON, J. (2000) "Da ditadura da oferta à democracia da demanda", Teoria e Sociedade, v. 6: 260-278.

WILKINSON, J.(2006) "Network theories and political economy: from attrition to converge", In MARSDEN, T. and MURDOCH, J., ed. Between the local and the global. Research in Rural Sociology and Development, Vol. 12, Oxford/UK: JAI Press. 